\title{
A quality of life index for inflammatory bowel disease
}

\author{
E JAN IRVINE, MD, FRCPC, MSC
}

EJ IRVINE. A quality of life index for inflammatory bowel disease. Can J Gastroenterol 1993;7(2):155-159. Health related quality of life (HRQOL) is a subjective quantitative measure of health perception and function in the physical, social and emotional domains. Such health status measures can be exploited to evaluate the natural history of disease, identify patient needs and research questions, quantify the effect of specific interventions in clinical trials and to monitor change. Conventional disease activity indices have failed to measure the impact of inflammatory bowel disease (IBD) and its consequences on family, social and working life. General measures of HRQOL fail to reflect impairment experienced by a young population with predominant gastrointestinal symptoms. A specific quality of life index for IBD patients - IBDQ - has been developed. The IBDQ contains 32 items in four domains (bowel, systemic, social and emotional) with responses graded on a seven-point Likkert scale from 7 (not a problem) to 1 (a severe problem). In 97 IBD patients bowel and systemic function were most notably impaired. A modified IBDQ was mailed to 182 well IBD patients and 48 normals. Total IBDQ and all dimensional scores were significantly worse in patients than in controls $(\mathrm{P}<0.01)$. Two clinical trials in Crohn's disease have used the IBDQ as an outcome measure of therapeutic efficacy. The largest, the Canadian Crohn's Relapse Prevention Trial, evaluated continuous low dose cyclosporine versus placebo in 305 patients and further established the IBDQ as a valid, reproducible and responsive measure. Changes in IBDQ scores paralleled changes in standard disease activity scores and changes in therapy. Similar correlations were observed in a trial of oral 5 -aminosalicylic acid or prednisone in mild to moderate ileocolonic Crohn's disease. Although the IBDQ has previously been interviewer-administered, preliminary analysis of anurse-administered versus a self-administered questionnaire suggests that either

Department of Medicine, Division of Gastroenterology, McMaster University, Hamilton, Ontario

Correspondence: Dr E Jan Irvine, Department of Medicine, Division of Gastroenterology, Room 4W8 - HSC, McMaster University, 1200 Main Street West, Hamilton, Ontario L8N 325. Telephone (416) 521-2100 ext 6402
TNFAMMATORY BOWEL DISEASE (IBD) is a group of chronic inflammatory diseases of the gastrointestinal tract which are multifactorial in etiol. ogy. Although ulcerative colitis and Crohn's disease represent the two predominant disease entities, approximately $10 \%$ of patients with colitis are classed as being indeterminate due to the presence of overlapping features $(1,2)$. The phenotypic expression of these diseases is highly variable and is often associated with a variety of autoimmune extraintestinal manifestations such as seronegative arthritis, uveitis and erythema nodosum (3). Complications of the disease commonly include stricture formation and obstruction, fistulization and malabsorption in Crohn's disease, or severe colonic hemorrhage, toxic megacolon and colorectal cancer in ulcerative colitis (4).

Irrespective of the clinically expressed syndromes, both Crohn's disease and ulcerative colitis have been identified as chronic disorders. Many patients experience frequent visits to physicians and/or recurrent hospitalizations for problems due to their intes- 
method detects clinically important change and that the IBDQ can be reliably self-administered after a brief training period. Therefore, the IBDQ reflects HRQOL and ought to be a critical outcome measure in all clinical trials of IBD. Future work in HRQOL to evaluate adverse drug effects or identify patient subgroups which might benefit from nondrug therapies is warranted.

Key Words: Activity index, Colitis ulcerative, Crohn's disease, Health-related quality of life

\section{Indice de qualité de vie et maladie intestinale inflammatoire}

RÉSUMÉ: La qualité de vie, dans son articulation avec la santé, est une mesure quantitative subjective de la perception que l'on a de la santé et du fonctionnement physique, social et émotionnel de l'individu. Ces paramètres peuvent être exploités pour évaluer l'histoire naturelle de la maladie, identifier les besoins du patient et les thèmes de recherche, mesurer l'effet d'interventions spécifiques dans des essais cliniques et surveiller l'évolution. Les indices classiques sur l'évolution de la maladie ont échoué à rendre compte des répercussions de la maladie intestinale inflammatoire sur la dynamique familiale, sociale et professionnelle. Les mesures générales en matière de qualité de vie ne reflètent pas toujours les problèmes dont fait l'expérience une population jeune qui présente des symptômes gastro-intestinaux importants. Un questionnaire sur la qualité de vie a été mis au point spécifiquement pour les patients atteints de maladies intestinales inflammatoires. Il renferme 32 points couvrant quatre aspects (intestinal, systémique, social et émotionnel) et les réponses sont classées en sept catégories selon une échelle de Likkert, qui va de 7 (non problématique) à 1 (problème grave). Chez 97 patients atteints de maladie intestinale inflammatoire, la fonction intestinale et systémique n'était pas considérablement affectée. Un questionnaire modifié a été posté à 182 patients atteints de maladie intestinale inflammatoire qui se sentaient bien et à 48 patients normaux. Les résultats globaux et les scores pluridimensionnels se sont révélés nettement pires chez les patients que chez les témoins $(\mathrm{P}, 01)$. Deux essais cliniques dans la maladie de Crohn ont utilisé ce questionnaire comme mesure d'efficacité thérapeutique, Le plus volumineux des deux, le Canadian Crohn's Relapse Prevention Trial, a évalué de la cyclosporine à faible dose en continu à du placebo chez 305 patients et a démontré que le questionnaire est valide, reproductible et sensible. La modification des scores de qualité de vie concordait avec la modification des scores d'activité de la maladie et avec le traitement. Des corrélations similaires ont été observées dans un essai sur l'acide 5-aminosalicylique et la prednisone dans la maladie de Crohn iléocolique de légère à modérée. Bien que le questionnaire ait précédemment été présenté par un examinateur, l'analyse préliminaire des scores obtenus lorsque le test était administré par une infirmière ou auto-administré par le patient lui-même donne à penser que les deux méthodes permettent de déceler un changement important au plan clinique, et que le questionnaire peut être auto-administré en toute confiance après un bref entraînement. Donc, le questionnaire reflète la qualité de vie à l'égard de la santé et doit dorénavant faire partie des essais cliniques sur la maladie intestinale inflammatoire. Il convient cependant de procéder à d'autres essais sur les paramètres de qualité de vie pour évaluer les effets médicamenteux indésirables et pour identifier les sous-groupes de patients qui bénéficieraient de traitements non médicamenteux.

tinal disease. Work absenteeism, added to the social isolation of long term invalidism, the need for expensive medications and recurrent hospitalizations, result in an increased financial burden and often reduced earning capacity, as well as stress due to uncertainties about future health (5).

A number of tools are available to assess the clinical impact of IBD. These encompass familiar instruments like the standard disease activity indices such as the Powell-Tuck index for ulcerative colitis or Crohn's disease activity index (CDAI) $(6,7)$. Garrett and Drossman (8) have summarized the limitations of these scales which have included lack of validation in some cases, substantial interobserver variability and inability to detect functional disability in the home, work or social settings. Some scales show poor responsiveness to change in clinical status and fail to gauge adequately symptoms of intestinal obstruction or perianal disease (8).

To capture adequately the full impact of $\mathrm{IBD}$, additional health status variables must be assessed. Psychosocial variables such as family and cultural practices, social support and coping skills and the presence of stressful life events contribute to overall health status. Complementary to indices of health status are instruments designed to demonstrate health related quality of life (HRQOL). While HRQOL measures may overlap considerably with health status indices, and include symptoms of general well being or specific disease related problems, other aspects are unique to quality of life measures. Functional capacity, health care utilization, biological measurements of activity and complications of the disease itself (including toxicity of therapy) comprise the attributes of quality of life (8). The HRQOL index, therefore, gives a broader perception of the IBD patient as a complete in. dividual.

\section{HEALTH RELATED QUALITY OF LIFE}

HRQOL is a concept originating from economics and cost utility theory. It connotes a subjective (patient-reported) quantitative measure of health perception or attitudes and function in the physical, social and emotional domains. Uncommonly, spouses, rela. tives, friends or physicians may act as proxy responders for patients. How. ever, this may considerably jeopardize the validity and reliability of these instruments.

Although development of HRQOL indices is in its infancy, momentum is gathering among patients, clinicians, researchers and health policy makers to apply such indices to identify patients needs, direct research questions and alter health care utilization. These health status measures can also be exploited to evaluate the natural history 
of disease, quantify the effect of specific interventions (as in clinical trials) and to monitor change in burden of disease, phenotypic expression or other features.

There are a variety of general measures of HRQOL such as the Sickness Impact Profile, RAND quality of life index, Nottingham Health Profile, McMaster Health Index, etc. Such general measures permit comparison of function or disability among diverse disease entities and populations. Drossman et al examined the Sickness Impact Profile, a general quality of life index, in 87 patients with Crohn's disease and 67 patients with ulcerative colitis and found that social and psychological dysfunction considerably outweighed physical disability (9). However, the physical dimension of the sickness Impact Profile index is more germane to an older population with impaired mobility and difficulty in performing activities of daily living, and is less sensitive to detect the gastrointestinal problems experienced by young patients with abdominal pain and bloody diarrhea. These results underscore the need to use an index which is more specific for the problems of Crohn's disease and ulcerative colitis. Nevertheless, there is merit in combining general with disease specific measures of HRQOL.

\section{HRQOL IN IBD}

There are well over 300 disease specific HRQOL indices which embody sensory function, mobility, physical, emotional, social and cognitive function, ability to undertake activities of daily living and level of pain and discomfort.

To overcome the deficiencies of many of the disease activity indices and general HRQOL measures, a disease specific quality of life index for IBD (IBDQ) was developed to measure treatment effects in clinical trials. The a priori specifications for this index were that it be quantitative, simple to administer, valid (ie, measuring HRQOL), reproducible and responsive to change. During the formulation of the IBDQ, 54 patients with Crohn's disease and 43 with ulcerative colitis,

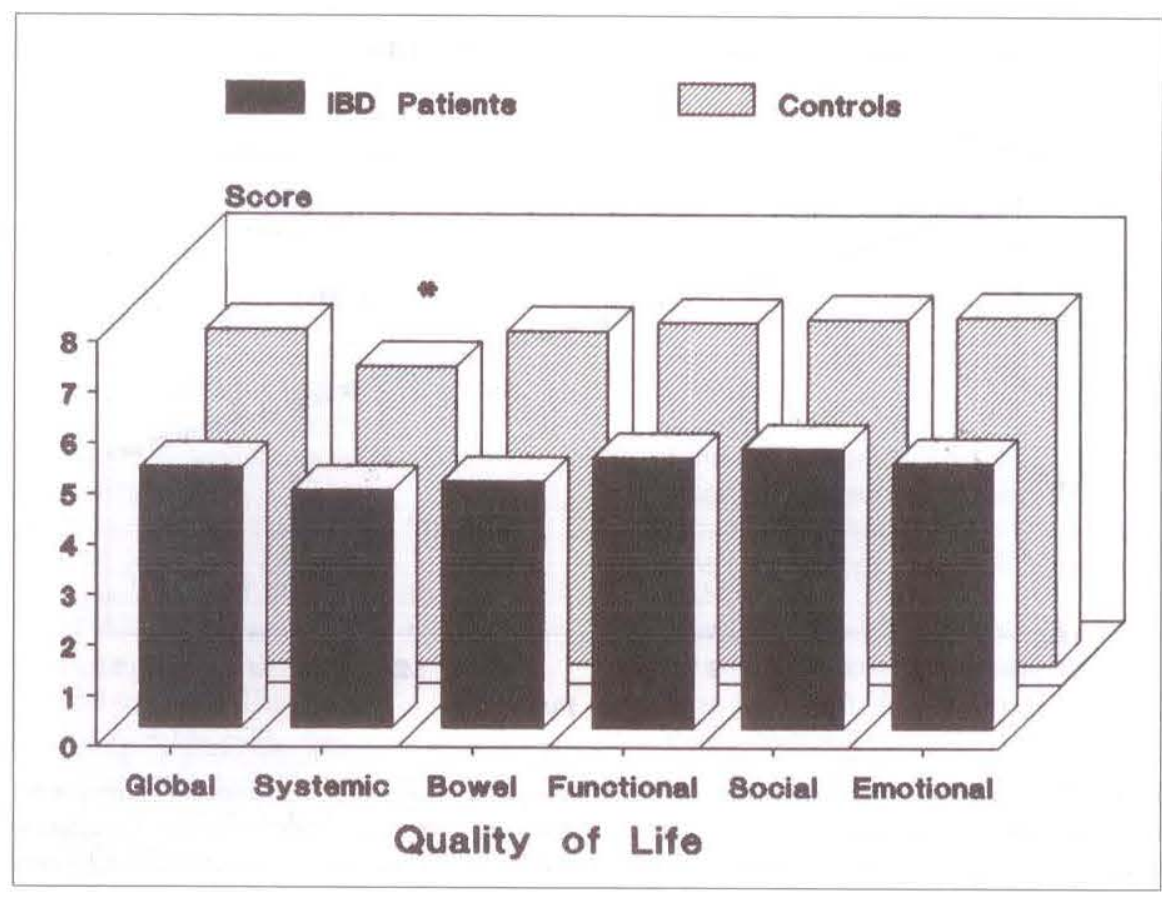

Figure 1) Inflammatory bowel disease quality of life (IBDQ) scores in 182 patients with IBD and 48 normal controls. Scores represent mean score per item for the global (total IBDQ) and each of five dimensional scores. ${ }^{*} P=0.01$ for score in IBD versus controls. All other scores were significant at $P<0.001$

\section{TABLE 1}

IBDQ scores in 42 clinically stable subjects

\begin{tabular}{lrrc}
\hline Score & Baseline & Week 8 & P value \\
\hline IBDQ & 168.09 & 169.10 & 0.28 \\
CDAI & 135.97 & 147.44 & 0.88 \\
HB & 4.41 & 4.59 & 0.06 \\
MDGA & 1.45 & 0.67 & 0.26 \\
\hline
\end{tabular}

Mean scores at study entry and first follow-up visit (week 8 ) in the Canadian Crohn's Relapse Prevention Trial. CDAICrohn's disease activity index: HB Harvey-Bradshaw index: $1 B D Q$ inflammatory bowel disease quality of life index: MDGA physician's global assessment (range 1-17); P value Scores compared using a student's 't' test for paired data

together with 10 health care providers including gastroenterologists, identified 150 problems experienced by patients with ulcerative colitis or Crohn's disease (10). These were then ranked by the IBD patients according to frequency and severity. In contrast to the findings of Drossman et al using the Sickness Impact Profile (9), the most notable problems were intestinal symptoms (bloating, diarrhea, abdominal pain), systemic problems (fatigue, weakness) and emotional dysfunction (feeling irritable or worried). Social dysfunction, although identified as a problem by patients, was less troublesome than the other categories. The final questionnaire, the IBDQ, contained 32 items within four dimensions (bowel, systemic, social and emotional) (11). Responses were graded on a seven-point Likkert scale from 7 (not a problem) through 1 (a very severe problem), giving a possible range of 32 to 224 , with a higher score indicative of better HRQOL.

\section{IBDQ IN CLINICAL RESEARCH}

To determine whether patients with IBD, who were not necessarily attending physicians or specialized clinics do indeed experience impaired quality of life, Love et al (12) conducted a mail survey of a local Canadian Foundation for Ileitis and Colitis chapter. One hundred and eighty-two (46\%) of those 


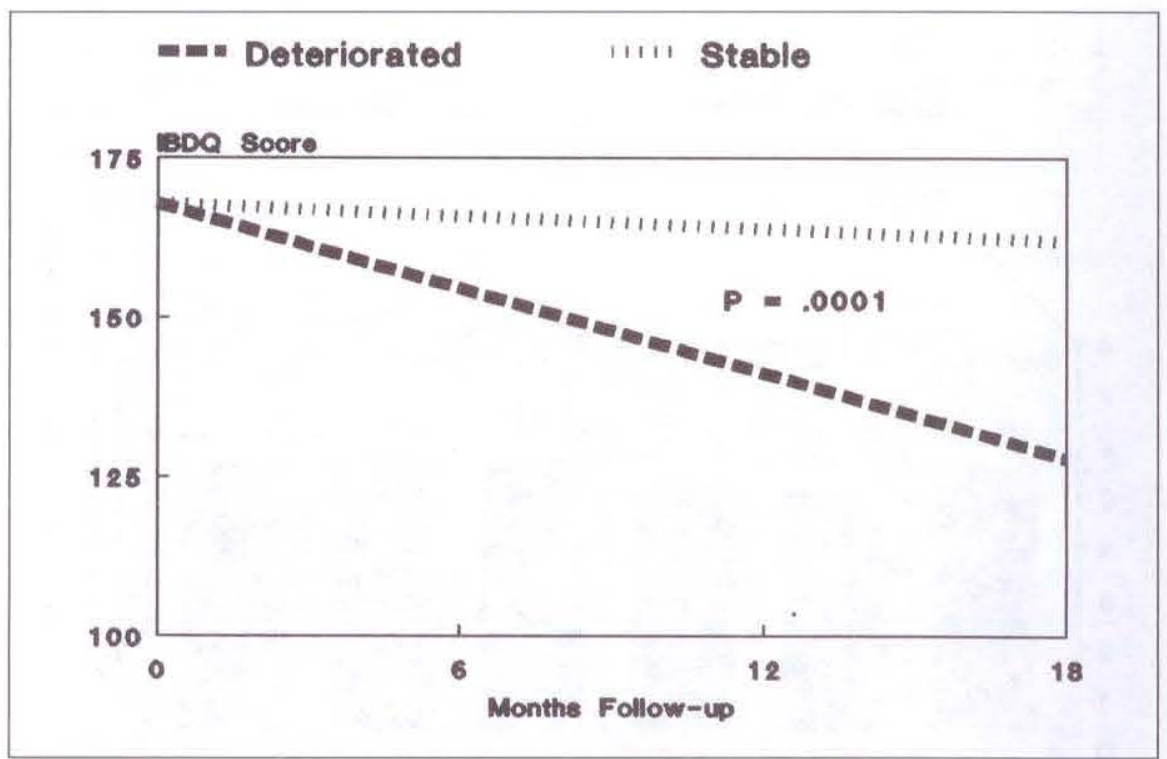

Figure 2) Comparison of inflammatory bowel disease quality of life (IBDQ) scores of patients who remained stable versus patients who deteriorated during the Canadian Crohn's Relapse Prevention. Trial (13). Lines represent the change in score between study entry and lowest achieved IBDQ scores

\section{TABLE 2}

\section{Nurse-administered versus self-administered IBDQ scores}

\begin{tabular}{lccc}
\hline & Nurse-administered & Self-administered & $\begin{array}{c}\text { Nurse- and } \\
\text { self-administered }\end{array}$ \\
\hline IBDQ & $158 \pm 39$ & $154 \pm 40$ & $3.7 \pm 5.7^{*}$ \\
Bowel & $4.9 \pm 1.3$ & $4.8 \pm 1.2$ & $0.1 \pm 0.2^{*}$ \\
Emotional & $5.0 \pm 1.3$ & $4.8 \pm 1.3$ & $0.1 \pm 0.2^{*}$ \\
Systemic & $4.2+1.5$ & $4.2 \pm 1.4$ & $0.0 \pm 0.4$ \\
Social & $5.5 \pm 1.5$ & $5.3 \pm 1.7$ & $0.2+0.6$ \\
\hline
\end{tabular}

Mean IBDQ scores in 63 patients with Crohn's disease or uicerative collitis comparing nurse-and self-administered scores. IBDQ score range 32 to 224 . Dimensional scores are mean response per item for 32 items with scores 1 to 7 . Higher score represents better quality of life. P<0.01 A difference of more than 0.5 per item is considered clinically significant

surveyed responded to a slightly modified IBDQ. Results were compared with 48 control subjects (hospital employees). The aggregate IBDQ score and all dimensional scores (Figure 1) were significantly worse $(\mathrm{P}<0.01)$ in the IBD group, with bowel and emotional function being most severely affected $(\mathrm{P}<0.001)$.

Two double-blind, randomized, controlled clinical trials in IBD have used the IBDQ as a secondary outcome measure of therapeutic efficacy - the intended application of the IBDQ. The largest study to date involving 305 patients - the Canadian Crohn's Relapse Prevention Trial - examined HRQOL in a multicentre trial evaluating the effect of continuous low dose cyclosporine (mean $4.8 \mathrm{mg} / \mathrm{kg} /$ day for
18 months) on Crohn's disease (13). Results of this trial have further established the IBDQ as a valid, reproducible and responsive measure (14). Changes in IBDQ scores parallelled those of the 'harder' conventional outcome measures such as standard disease activity scores (CDAI, $\mathrm{r}=-0.59$; $\mathrm{P}<0.0001$ ), changes in therapy and patient $(\mathrm{r}=0.42 ; \mathrm{P}<0.0001)$ and physician global assessments $(\mathrm{r}=0.35$; $\mathrm{P}<0.0001$ ). In 134 patients who remained stable throughout this trial, there was no statistical change in IBDQ scores with time $(\mathrm{P}=0.55)$. The intraclass correlation coefficient of the overall IBDQ score in 42 stable patients (Table 1) was high $($ rho $=0.67)$, illustrating good reproducibility and limited observer bias. Patients who deteriorated during the study $(\mathrm{n}=171)$ experienced a significant worsening of their IBDQ score between study entry and time of exacerbation $(\mathrm{P}=0.0001)$ (Figure 2). In a smaller study evaluating oral 5-aminosalicylic acid (Salofalk; Interfalk Canada) $3 \mathrm{~g} /$ day versus a standard dose of prednisone over 12 weeks in 50 patients with mild and moderate Crohn's ileocolitis, the IBDQ im. proved similarly in both treatment groups as did the CDAI (15). There was a significant improvement in systemic symptoms and overall IBDQ scores after the first two weeks in the steroid treated group, which was attributed to the initial effects of prednisone on mood and well being.

To date, the IBDQ and other HRQOL measures have been predominantly interviewer administered. Preliminary assessment of the IBDQ as a self administered questionnaire compared with results when nurse administered demonstrated in 63 patients with Crohn's disease or ulcerative colitis that results were clinically similar using either method (Table 2). Thus, the IBDQ can be reliably self-administered after a brief training period (16). This is supported by the results of Martin et al (15) who used a self-administered IBDQ, although without prior validation.

From the preceding results, it is concluded that the IBDQ reflects HRQOL extending beyond traditional disease activity indices to include social, emotional and functional dimensions. Quality of life appears to be impaired in patients with inflam. matory bowel disease in contrast to normal subjects. The IBDQ is a valid, reliable and responsive measure of outcome which has been used as a quantitative outcome in clinical trials of IBD. Future work in this field might be directed towards exploring the development of yet more focused HRQOL measures, eg, for patients with fistulae or perianal disease, the application of HRQOL in evaluation of adverse or unexpected beneficial drug effects, or in the identification of patient subgroups which might benefit from nondrug or alternative therapies. 


\section{REFERENCES}

1. Kirsner JB. Problems in the differentiation of ulcerative colitis and Crohn's disease of the colon: The need for repeated diagnostic evaluation. Gastroenterology 1975;68:187-91. (Edit)

2. Clamp SE, Myren J, Bouchier I, Watkinson G, DeDombal F. Diagnosis of inflammatory bowel disease: An international multi-centre scoring system. Br Med J 1982;284:91-5

3. Greenstein AJ, Janowitz HD, Sachar DB. The extraintestinal complications of Crohn's disease and ulcerative colitis: A study of 700 patients. Medicine 1976;55:401-12.

4. Huizenga KA, Schroeder KW. Gastrointestinal complications of ulcerative colitis and Crohn's disease. In: Kirsner JB, Shorter RG, eds. Inflammatory Bowel Disease. Philadelphia: Lea \& Febiger. 1988:257-80.

5. Kirsner JB. Observations in medical treatment of inflammatory bowel disease. JAMA 1980;243:557-63
6. Powell-Tuck J, Brown RL, LennardJones JE. A comparison of oral prednisone given as single or multiple daily doses for active proctocolitis. Scand J Gastroenterol 1978;13:833-7.

7. Best WR, Becktel JM, Singleton JW. Rederived values of the eight coefficients of the Crohn's disease activity index (CDAI). Gastroenterology 1979;77:843-6.

8. Garrett JW, Drossman DA. Health status in inflammatory bowel disease: Biological and behavioural considerations. Gastroenterology 1990;99:90-6.

9. Drossman DA, Patrick DL, Mitchell CM, Murp EA, Zagomi EA, Appelbaum MI. Health related quality of life in inflammatory bowel disease: Functional status and patient worries and concerns. Dig Dis Sci 1989;34:1379-86.

10. Mitchell A, Guyatt G, Singer J, Irvine EJ, et al. Quality of life in patients with inflammatory bowel disease. J Clin Gastroenterol 1988;10:306-10.

11. Guyatt GH, Mitchell A, Irvine EJ, et al. A new measure of health status for clinical trials in inflammatory bowel disease. Gastroenterology 1989;96:804-10.

12. Love JR, Irvine EJ, Fedorak RN. Quality of life in inflammatory bowel disease. J Clin Gastroenterol 1992;14:15-19.

13. Archambault A, Feagan B, Fedorak R, et al. The Canadian Crohn's Relapse Prevention Trial (CCRPT). Gastroenterology 1991;100:A193. (Abst)

14. Irvine EJ, Feagan B, Rochon J, et al. Quality of life adds dimension to outcome in clinical trials of IBD. Gastroenterology 1992;102:A640. (Abst)

15. Martin F, Sutherland L, Beck IT, et al. Oral 5-ASA versus prednisone in short term treatment of Crohn's disease: A multicentre controlled trial. Can J Gastroenterol 1990;4:452-7.

16. Irvine EJ, Feagan B, Wong C. Should quality of life instruments be self-administered? Falk Symposium No. 66, Quebec City, May 1992:25. (Abst) 


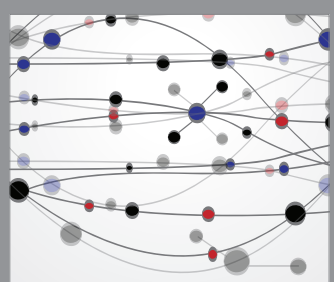

The Scientific World Journal
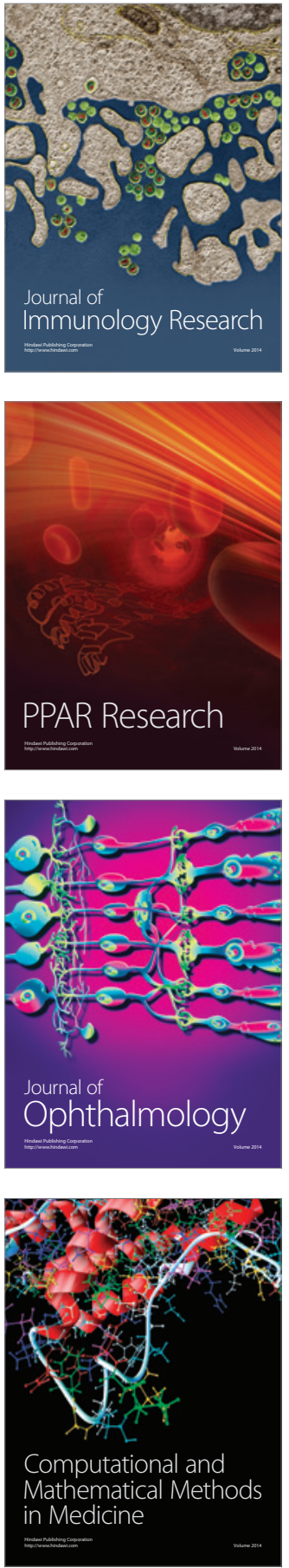

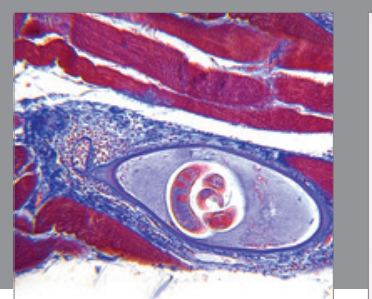

Gastroenterology Research and Practice

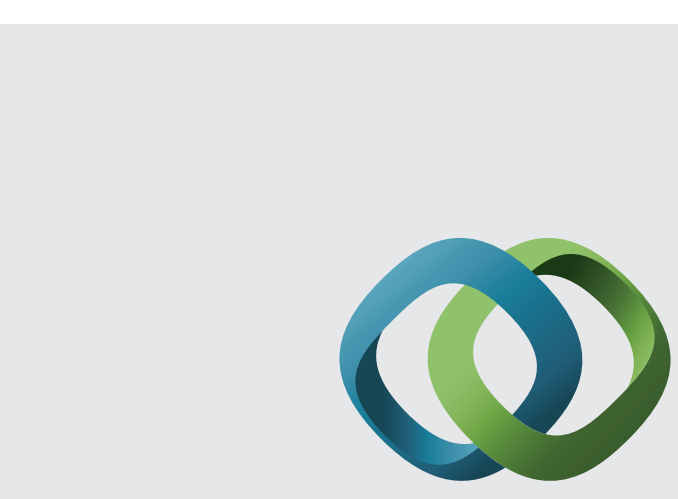

\section{Hindawi}

Submit your manuscripts at

http://www.hindawi.com
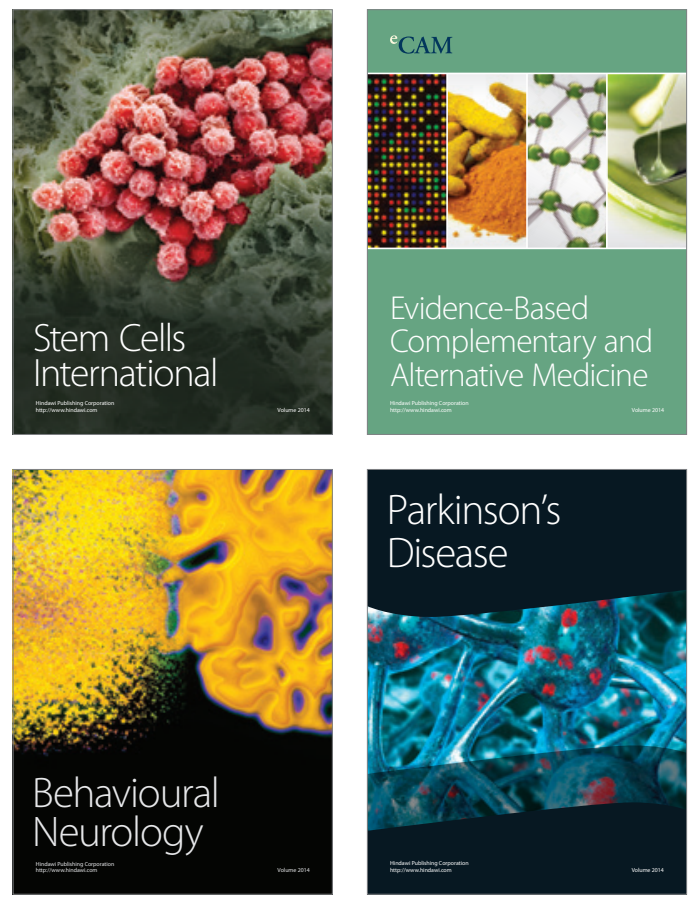
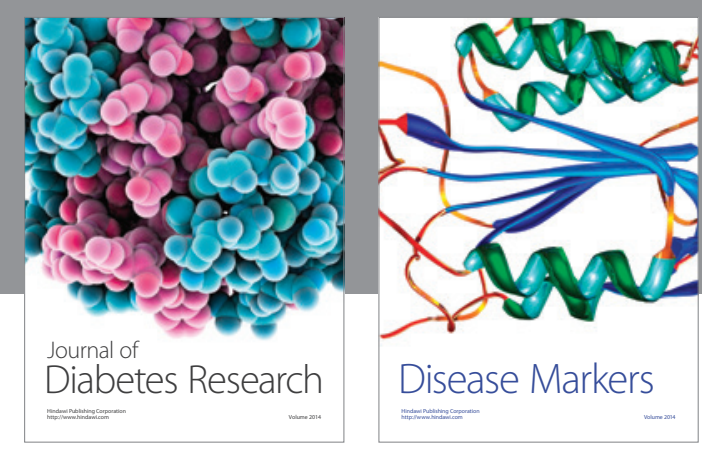

Disease Markers
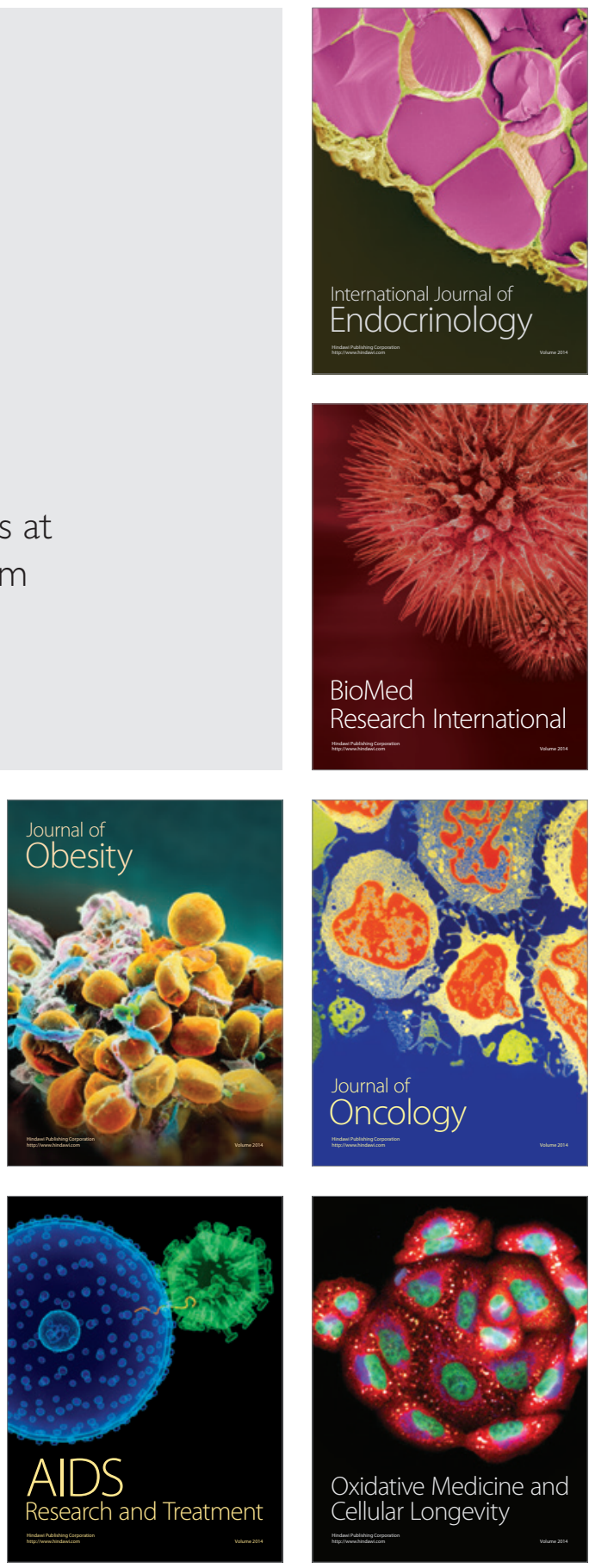